\title{
TITIK TETAP INVERS TRANSFORMASI BILINEAR DAN TRANSFORMASI BILINEAR KONJUGAT
}

\section{Fixed Point of Invers Bilinear Transformation and Conjugate Bilinear Transformation}

\author{
Ahmad Ansar ${ }^{1 *}$ \\ ${ }^{1}$ Prodi Matematika, FMIPA, Universitas Sulawesi Barat \\ Jln. Prof. Dr. Baharuddin Lopa, SH Talumung, Majene, 91411, Indonesia \\ e-mail: 1*ahmad.ansar@unsulbar.ac.id \\ Corresponding author*
}

\begin{abstract}
Abstrak
Transformasi bilinear merupakan salah satu transformasi dasar yang dipelajari di analisis fungsi kompleks dan memiliki banyak aplikasi dalam berbagai bidang. Pada tulisan ini dibahas terkait titik tetap transformasi bilinear beserta beberapa sifat-sifatnya. Hasil yang diperoleh selanjutnya digunakan untuk menyelidiki titik tetap invers tranformasi bilinear beserta beberapa sifat-sifatnya. Dalam tulisan ini juga dijelaskan terkait titik tetap transformasi bilinear konjugat.
\end{abstract}

Kata Kunci : titik tetap, invers transformasi bilinear, transformasi bilinear konjugat.

Abstract

Bilinear transformation is one of the basic transformations studied in complex function analysis and it has many applications in various fields. This article discusses about the fixed point of bilinear transformation and its properties. The results obtained are used to investigating the fixed point invers bilinear transformation. This article also explains the fixed point of the conjugate bilinear transformation.

Keywords: Fixed point, Invers bilinear transformation, Conjugate bilinear transformation. 


\section{PENDAHULUAN}

Transformasi bilinear merupakan salah satu transformasi dasar yang dipelajari di analisis fungsi kompleks dan memiliki banyak aplikasi dalam berbagai bidang seperti persamaan diferensial, geometri hyperbolik, teknik, dan fisika. Transformasi bilinear digunakan dalam image processing dan kriptografi seperti yang dijelaskan oleh Lin dan Chen dalam [1]. Pengembangan teori transformasi bilinear sangat penting untuk memberikan referensi dan kajian baru sehingga dapat diaplikasikan dalam bidang lain.

Beberapa artikel yang membahas terkait pengembangan transformasi bilinear antara lain artikel Niamsup [2] dan Jing [3] yang membahas karakteristik transformasi bilinear serta artikel Mackey dkk [4] menjelaskan transformasi Mobius dari matriks polinomial. Selain itu, Demirel [5] memberikan penjelasan terkait transformasi bilinear dalam kaitannya dengan geometri hiperbolik dan Kaur [6] menjelaskan terkait sifat-sifat dari transformasi bilinear dan Ozgur [7] menjelaskan sifat grup Mobius transformasi. Artikel lain yang menbahas tranformasi bilinear atau tranformasi Mobius dapat dilihat dalam [8]-[11] . Secara umum, penelitian dan pengembangan terhadap transformasi bilinear meliputi pemetaan transaformasi bilinear, titik tetap transformasi bilinear, transformasi bilinear konjugat dan sifat-sifat lain yang terkait. Tulisan ini akan membahas terkait titik tetap transformasi bilinear dalam hubungannya dengan inversnya dan transformasi bilinear konjugat.

Berikut diberikan definisi transformasi bilinear beserta beberapa sifat-sifatnya.

Definisi 1 [12]. Jika $a, b, c, d \in \mathbf{C}$ dengan $a d-b c \neq 0$, maka fungsi

disebut transformasi bilinear.

$$
T(z)=\frac{a z+b}{c z+d}
$$

Transformasi bilinear sering juga disebut transformasi fraksional linear atau transformasi Mobius. Jika $a d-b c=1$, maka $T(z)$ disebut trasformasi bilinear normal. Setiap transformasi bilinear dapat ditulis ke dalam bentuk normal dengan cara membagi bilangan $a, b, c, d \in \mathbf{C}$ pada $T(z)$ dengan $\sqrt{a d-b c}$. Dalam [13], dijelaskan bahwa jika $c \neq 0$, maka transformasi bilinear dapat ditulis dalam bentuk

$$
T(z)=\frac{a}{c}+\frac{b c-a d}{c^{2}} \frac{1}{z+\frac{d}{c}} .
$$

Hal ini, menunjukkan bahwa transformasi bilinear merupakan komposisi dari beberapa tranformasi elementer yaitu translasi oleh $T_{1}(z)=z+\frac{d}{c}$, transformasi oleh $T_{2}(z)=\frac{1}{z}$, transformasi oleh $T_{3}(z)=k z$, dan transformasi oleh $T_{4}(z)=\frac{a}{c}+z$. Transformasi bilinear yang dibahas dalam artikel ini adalah transformasi pada himpunan $\mathbf{C}^{*}=\mathbf{C} \cup\{\infty\}$. Oleh karena itu, didefinisikan $T(\infty)=\frac{a}{c}$.

Untuk menentukan transformasi bilinear, kita dapat digunakan metode (perbandingan silang) crossratio.

Definisi 2 [12]. Perbandingan silang (cross-ratio) dari bilangan-bilangan kompleks $z, z_{1}, z_{2}$ dan $z_{3}$ adalah bilangan kompleks $\left(z, z_{1}, z_{2}, z_{3}\right)=\frac{z-z_{1}}{z_{1}-z_{2}} \frac{z_{2}-z_{3}}{z_{3}-z}=\frac{z-z_{1}}{z-z_{3}} \frac{z_{2}-z_{3}}{z_{2}-z_{1}}$.

Berikut diberikan teorema terkait perbandingan silang

Teorema 1 [12]. Jika $w=T(z)$ adalah transformasi bilinear yang memetakan $z_{1}, z_{2}$ dan $z_{3}$ ke $w_{1}, w_{2}$ dan $w_{3}$ secara berturut-turut, maka untuk setiap $z \in \mathbf{C}$ berlaku

$$
\left(z, z_{1}, z_{2}, z_{3}\right)=\frac{z-z_{1}}{z-z_{3}} \frac{z_{2}-z_{3}}{z_{2}-z_{1}}=\frac{w-w_{1}}{w-w_{3}} \frac{w_{2}-w_{3}}{w_{2}-w_{1}}=\left(w, w_{1}, w_{2}, w_{3}\right)
$$

Syarat $a d-b c \neq 0$ pada transformasi bilinear menjamin bahwa transformasi bilinear $T(z)$ mempunyai invers. 
Definisi 3. Jika $T(z)=\frac{a z+b}{c z+d}$ adalah transformasi bilinear, maka invers transformasi bilinear didefinisikan sebagai

$$
T^{-1}(z)=\frac{-d z+b}{c z-a}
$$

Pada tulisan ini akan dibahas terkait titik tetap transformasi bilinear dan titik tetap invers transformasi bilinear serta hubungan antar keduanya. Selain itu, dijelaskan beberapa sifat-sifat terkait titik tetap invers transformasi bilinear. Selanjutnya, dijelaskan titik tetap transformasi bilinear konjugat.

\section{METODE PENELITIAN}

Penelitian ini adalah penelitian kajian literatur. Dalam peneltian ini dilakukan pengembangan dari hasil-hasil yang telah ada dari berbagai buku dan artikel terkait transformasi bilinear. Sifat-sifat titik tetap transformasi bilinear yang dipelajari terlebih dahulu. Hasil yang diperoleh kemudian digunakan dalam menyelidiki hubungannya dengan titik tetap invers transformasi bilinear. Selanjutnya, diselidiki titik tetap transformasi bilinear konjugat. Pembuktian beberapa teorema dibuat dengan lebih rinci.

\section{HASIL DAN PEMBAHASAN}

\subsection{Titik tetap transformasi bilinear}

Pada bagian ini dijelaskan mengenai beberapa sifat terkait titik tetap pemetaan transformasi bilinear. Pembahsan dimulai dari definisi titik tetap transformasi bilinear.

Definisi 4. Titik $z_{0} \in \mathbf{C}^{*}$ disebut titik tetap (titik invariant) transformasi bilinear apabila $T\left(z_{0}\right)=z_{0}$.

Jika $z_{0} \in \mathbf{C}^{*}$ adalah titik tetap transformasi bilinear maka $z_{0}=\frac{a z_{0}+b}{c z_{0}+d}$, sehingga diperoleh

$$
c z_{0}^{2}+(d-a) z_{0}-b=0
$$

Berdasarkan persamaan (5), titik tetap transformasi bilinear $T(z)$ paling banyak memiliki dua titik tetap yang nilanya ditentukan oleh nilai $c$ dan $D=(d-a)^{2}+4 b c$. Dalam [14] dijelaskan bahwa transformasi bilinear $T(z)$ memiliki

1. Dua titik tetap berhingga apabila $c \neq 0$ dan $D \neq 0$

2. Satu titik tetap berhingga apabila $c \neq 0$ dan $D=0$

3. Satu titik tetap berhingga dan satu titik tetap tak berhingga apabila $c=0$ dan $a-d \neq 0$

4. Satu titik tetap tak berhingga apabila $c=0$ dan $a-d=0$

Komposisi transformasi bilinear didefinisikan sebagai $T^{2}(z)=T(T(z))$. Jika $z_{0}$ titik tetap dari transformasi bilinear $T(z)$, maka $T^{2}\left(z_{0}\right)=T\left(T\left(z_{0}\right)\right)=T\left(z_{0}\right)=z_{0}$. Jadi $z_{0}$ juga merupakan titik tetap transformasi $T^{2}(z)$. Akibatnya, $z_{0}$ juga merupakan titik tetap transformasi $T^{n}(z)$ untuk setiap $n \in \mathbf{N}$.

Jika $T(z)$ adalah transformasi bilinear (1), maka

$$
\begin{aligned}
T^{2}(z)=T(T(z)) & =\frac{a\left(\frac{a z+b}{c z+d}\right)+b}{c\left(\frac{a z+b}{c z+d}\right)+d} \\
& =\frac{a^{2} z+a b+b c z+b d}{a c z+c b+d c z+d^{2}}
\end{aligned}
$$


Titik tetap transformasi $T^{2}(z)$ diperoleh dengan cara menyamakan persamaan (6) dengan $z$, yaitu $z=\frac{\left(a^{2}+b c\right) z+b(a+d)}{(a c+d c) z+c b+d^{2}}$. Diperoleh

$$
(a c+d c) z^{2}+\left(d^{2}-a^{2}\right) z-b(a+d)=0
$$

Jadi $z_{1 ; 2}=\frac{a-d+\sqrt{(a-d)^{2}+4 b c}}{2 c}$.

Berdasarkan Persamaan (7), terdapat beberapa kemungkinan nilai $z$ yang merupakan titik tetap $T^{2}(z)$ yaitu:

1. Jika $c \neq 0, a+d \neq 0$ dan $(d-a)^{2}+4 b c \neq 0$, maka transformasi $T^{2}(z)$ memliki 2 titik tetap yang berhingga dan titik tetap tersebut sama dengan titik tetap transformasi bilinear $T(z)$.

2. Jika $c \neq 0, a+d \neq 0$ dan $(d-a)^{2}+4 b c=0$, maka transformasi $T^{2}(z)$ memliki 1 titik tetap yang berhingga dan titik tetap tersebut sama dengan titik tetap transformasi bilinear $T(z)$.

3. Jika $c=0, a+d=0$ dan $a-d \neq 0$ maka $T^{2}(z)=\frac{a^{2} z+b(a+d)}{d^{2}}$. Jadi $\infty \in \mathbf{C}^{*}$ merupakan titik tetap $T^{2}(z)$. Titik tetap yang lain adalah $z_{0}=\frac{b}{d-a}$. Jadi transformasi $T^{2}(z)$ memliki 1 titik tetap berhingga dan 1 titik tetap takberhingga dimana titik tetap tersebut sama dengan titik tetap transformasi bilinear $T(z)$.

4. Jika $c=0$, serta $a+d=0$ dan $a-d=0$ maka transformasi $T^{2}(z)$ memiliki satu titik tetap takberhingga.

Transformasi bilinear $T(z)$ dapat ditentukan menggunakan perbandingan silang (cross-ratio). Dalam [14] dijelaskan bahwa transformasi bilinear $T(z)$ yang memiliki titik tetap berhingga $z_{0}$ dan $z_{1}$ dapat ditulis dalam bentuk yang lain. Hal ini dijelaskan dalam teorema berikut.

Teorema 2 [14]. Jika transformasi bilinear $w=T(z)$ memiliki titik tetap berhingga $z_{0}$ dan $z_{1}$ maka transformasi bilinear tersebut dapat ditulis dalam bentuk

$$
\frac{w-z_{0}}{w-z_{1}}=M \frac{z-z_{0}}{z-z_{1}}
$$

dengan $M=\frac{\left(z_{0}-T(\alpha)\right)\left(z_{1}-\alpha\right)}{\left(z_{1}-T(\alpha)\right)\left(z_{0}-\alpha\right)}$ untuk sebarang $\alpha \in \mathbf{C}$.

Bukti. Diketahui $w=T(z)$ memiliki titik tetap berhingga yaitu $z_{0}$ dan $z_{1}$. Misalkan $\alpha \in \mathbf{C}$, menggunakan prinsip perbandingan silang, maka

Diperoleh

$$
\begin{gathered}
\left(w, z_{0}, T(\alpha), z_{1}\right)=\left(z, z_{0}, \alpha, z_{1}\right) \\
\frac{w-z_{0}}{w-z_{1}} \frac{T(\alpha)-z_{1}}{T(\alpha)-z_{0}}=\frac{z-z_{0}}{z-z_{1}} \frac{\alpha-z_{1}}{\alpha-z_{0}}
\end{gathered}
$$

$$
\frac{w-z_{0}}{w-z_{1}}=\frac{\alpha-z_{1}}{\alpha-z_{0}} \frac{T(\alpha)-z_{0}}{T(\alpha)-z_{1}} \frac{z-z_{0}}{z-z_{1}}
$$


Bilangan $M$ disebut pengali dari transformasi bilinear $T(z)$ yang memiliki dua titik tetap berhingga. Teorema berikut menjelaskan hubungan antara pengali transformasi biliniar $T(z)$ dengan inversnya.

Teorema 3. Diketahui transformasi bilinear $T(z)$ yang memiliki dua titik tetap berhingga. Jika M adalah pengali transformasi bilinear $T(z)$, maka pengali transformasi bilinear $T^{2}(z)$ adalah $M^{2}$.

Bukti. Diketahui $M$ adalah pengali transformasi bilinear $w=T(z)$. Diperoleh

$$
\frac{T^{2}(z)-z_{0}}{T^{2}(z)-z_{1}}=\frac{T(w)-z_{0}}{T(w)-z_{1}}=M \frac{w-z_{0}}{w-z_{1}}=M \cdot M \frac{z-z_{0}}{z-z_{1}} .
$$

Jadi pengali $T^{2}(z)$ adalah $M^{2}$ dengan $M=\frac{\left(z_{0}-T(\alpha)\right)\left(z_{1}-\alpha\right)}{\left(z_{1}-T(\alpha)\right)\left(z_{0}-\alpha\right)}$ untuk sebarang $\alpha \in \mathbf{C}$.

Akibat 4. Diketahui transformasi bilinear $T(z)$ yang memiliki dua titik tetap berhingga. Jika M adalah pengali transformasi bilinear $T(z)$, maka pengali transformasi bilinear $T^{n}(z)$ adalah $M^{n}$ untuk suatu bilangan asli $n$.

Teorema berikut merupakan penjelasan lain dari teorema yang ada dalam [13] dan teorema yang ada di dalam [14]. Dalam [13], transformasi $T(z)$ merupakan bentuk normal sedangkan teorema berikut adalah transformasi bilinear yang umum.

Teorema 5 [13]. Jika transformasi bilinear $T(z)$ memiliki satu titik tetap berhingga $z_{0}$ maka transformasi bilinear $w=T(z)$ dapat ditulis dalam bentuk

$$
\frac{\left(w-z_{0}\right)}{(w-z)}=P \frac{1}{\left(z-z_{0}\right)}
$$

dengan $P=-\frac{\left(d+c z_{0}\right)}{c}$.

Bukti. Diketahui $w=T(z)$ memiliki satu titik tetap yaitu $z_{0}$. Karena $T(z)$ hanya memiliki satu titik tetap maka persamaan (5) dapat ditulis dalam bentuk $c\left(z-z_{0}\right)^{2}=0$. Akibatnya diperoleh $a=d+2 c z_{0}$ dan $b=-c z_{0}^{2}$. Diperoleh

dengan menjabarkan bentuk di atas, maka

$$
w=\frac{\left(d+2 c z_{0}\right) z-c z_{0}^{2}}{c z+d}
$$

$$
\begin{aligned}
c w z+d w=d z+2 c z_{0} z-c z_{0}^{2} & \Leftrightarrow c\left(w-z_{0}\right)\left(z-z_{0}\right)+c w z_{0}+c z_{0} z-c z_{0}^{2}+w d=d z+2 c z_{0} z-c z_{0}^{2} \\
& \Leftrightarrow c\left(w-z_{0}\right)\left(z-z_{0}\right)+c w z_{0}+w d=d z+c z_{0} z \\
& \Leftrightarrow c\left(w-z_{0}\right)\left(z-z_{0}\right)=c z_{0}(z-w)+d(z-w) \\
& \Leftrightarrow c\left(w-z_{0}\right)\left(z-z_{0}\right)=-(w-z)\left(d+c z_{0}\right) \\
& \Leftrightarrow\left(w-z_{0}\right)\left(z-z_{0}\right)=-\frac{\left(d+c z_{0}\right)}{c}(w-z) \\
& \Leftrightarrow \frac{\left(w-z_{0}\right)}{(w-z)}=-\frac{\left(d+c z_{0}\right)}{c} \frac{1}{\left(z-z_{0}\right)} .
\end{aligned}
$$

Jadi transformasi bilinear $T(z)$ memiliki satu titik tetap berhingga $z_{0}$, dapat ditulis dalam bentuk $\frac{\left(w-z_{0}\right)}{(w-z)}=P \frac{1}{\left(z-z_{0}\right)}$ dengan $P=-\frac{\left(d+c z_{0}\right)}{c}$.

Dalam [14] dijelaskan bentuk transformasi bilinear yang memiliki satu titik tetap berhingga dan satu titik tetap tak berhingga memiliki bentuk alternatif seperti yang dijelaskan dalam teorema berikut. 
Teorema 6. Jika transformasi bilinear $T(z)$ memiliki satu titik tetap berhingga $z_{0}$ dan satu titik titik tetap takberhingga, maka transformasi bilinear $w=T(z)$ dapat ditulis dalam bentuk $\left(w-z_{0}\right)=R\left(z-z_{0}\right)$ dengan $R=\frac{a}{d}$.

Bukti. Karena $w=T(z)$ memiliki satu titik tetap berhingga $z_{0}$ dan satu titik titik tetap takberhingga, maka

$$
w=\frac{a}{d} z+\frac{b}{d}
$$

Karena $z_{0}$ titik titik tetap $w=T(z)$, maka $z_{0}=\frac{a}{d} z_{0}+\frac{b}{d}$.

Dari (14) diperoleh

$$
w-z_{0}=\frac{a}{d}\left(z-z_{0}\right) .
$$

Jadi transformasi bilinear $w=T(z)$ dapat ditulis dalam bentuk $\left(w-z_{0}\right)=R\left(z-z_{0}\right)$ dengan $R=\frac{a}{d} . \square$

\subsection{Titik tetap invers transformasi bilinear}

Pada bagian ini akan dijelaskan terkait beberapa sifat titik tetap invers transformasi bilinear.

Teorema 7. Jika $z_{0} \in \mathbf{C}^{*}$ adalah titik tetap transformasi linear $T(z)$, maka $z_{0}$ juga merupakan titik tetap dari $T^{-1}(z)$.

Bukti. Karena $z_{0}$ adalah titik tetap transformasi $T(z)$, maka

$$
z_{0}=T\left(z_{0}\right)=\frac{a z_{0}+b}{c z_{0}+d}
$$

Diperoleh $c z_{0} T\left(z_{0}\right)+d T\left(z_{0}\right)=a z_{0}+b$ atau

$$
z_{0}=\frac{-d T\left(z_{0}\right)+b}{c T\left(z_{0}\right)-a}
$$

Karena $T\left(z_{0}\right)=z_{0}$, maka

$$
z_{0}=\frac{-d z_{0}+b}{c z_{0}-a}
$$

Jadi $z_{0}$ adalah titik tetap transformasi $T^{-1}(z)=\frac{-d z+b}{c z-a}$.

Teorema 8. Diketahui transformasi bilinear $T(z)$ yang memiliki dua titik tetap berhingga. Jika M adalah pengali transformasi bilinear $T(z)$, maka $\frac{1}{M}$ adalah pengali transformasi bilinear $T^{-1}(z)$.

Bukti 1. Misalkan $z_{0}, z_{1}$ adalah titik tetap transformasi bilinear $T(z)$. Berarti $z_{0}$ dan $z_{1}$ juga merupakan titik transformasi bilinear $T^{-1}(z)$. Berarti

$$
\begin{aligned}
& \frac{T^{-1}(z)-z_{0}}{T^{-1}(z)-z_{1}}=N \frac{z-z_{0}}{z-z_{1}}, \\
& \text { dengan } N=\frac{\left(z_{0}-T^{-1}(\alpha)\right)\left(z_{1}-\alpha\right)}{\left(z_{1}-T^{-1}(\alpha)\right)\left(z_{0}-\alpha\right)} \text { untuk sebarang } \alpha \in \mathbf{C} \text {. Akibatnya } \\
& N=\frac{1}{\frac{\left(z_{1}-T^{-1}(\alpha)\right)\left(z_{0}-\alpha\right)}{\left(z_{0}-T^{-1}(\alpha)\right)\left(z_{1}-\alpha\right)}}=\frac{1}{\frac{\left(z_{0}-T^{-1}(T(\alpha))\right)\left(z_{1}-T^{-1}(\alpha)\right)}{\left(z_{1}-T^{-1}(T(\alpha))\right)\left(z_{0}-T^{-1}(\alpha)\right)}}=\frac{1}{M} .
\end{aligned}
$$




\section{Bukti 2:}

Diketahui M adalah pengali transformasi bilinear $w=T(z)$, berarti

$\frac{w-z_{0}}{w-z_{1}}=M \frac{z-z_{0}}{z-z_{1}}$. Diperoleh

$\frac{w-z_{0}}{w-z_{1}}=M \frac{T^{-1}(w)-z_{0}}{T^{-1}(w)-z_{1}} \Leftrightarrow \frac{T^{-1}(w)-z_{0}}{T^{-1}(w)-z_{1}}=\frac{1}{M} \frac{w-z_{0}}{w-z_{1}}$.

Jadi $\frac{1}{M}$ adalah pengali transformasi bilinear $T^{-1}(z)$.

\subsection{Titik tetap transformasi bilinear konjugat}

Pada bagian ini akan diberikan beberapa teorema terkait titik tetap dari konjugat transformasi bilinear.

Definisi 5 [15]. Konjugat dari bilangan kompleks $z=x+$ iy dengan $x, y \in \mathbf{R}$, ditulis $\bar{z}$, didefinisikan sebagai $\bar{z}=x-i y$.

Definisi 6 [13]. Jika $T(z)$ adalah transformasi bilinear, maka transformasi bilinear konjugat didefinisikan sebagai

$$
\bar{T}(z)=\frac{a \bar{z}+b}{c \bar{z}+d}
$$

dengan $a d-b c \neq 0$.

Transformasi bilinear konjugat merupakan komposisi dari transformasi bilinear $T(z)$ dengan transformasi $K(z)=\bar{z}$. Transformasi bilinear konjugat dapat diubah kedalam bentuk normal, $a d-b c=1$, dengan cara membagi bilangan $a, b, c, d \in \mathbf{C}$ dengan $\sqrt{a d-b c}$. Dalam tulisan ini, diasumsikan transformasi bilinear konjugat $\bar{T}(z)$ adalah normal. Berikut diberikan beberapa teorema terkait titik tetap transformasi bilinear konjugat.

Teorema 9 [13]. Diberikan transformasi bilinear konjugat $\bar{T}(z)$. Jika $c \neq 0, \bar{a}+d \neq 0$ dan $D=\left(|a|^{2}+|d|^{2}+b \bar{c}+\bar{b} c\right)^{2}-4 \neq 0$, maka $\bar{T}(z)$ mempunyai dua titik tetap yang berhingga.

Bukti. Misalkan $z_{0}$ adalah titik tetap dari $\bar{T}(z)$, berarti

atau

$$
z_{0}=\frac{a \overline{z_{0}}+b}{c \overline{z_{0}}+d}
$$

$$
\overline{z_{0}}=\overline{\bar{T}\left(z_{0}\right)}=\overline{\left(\frac{a \overline{z_{0}}+b}{c \overline{z_{0}}+d}\right)}=\frac{\bar{a} z_{0}+\bar{b}}{\bar{c} z_{0}+\bar{d}} .
$$

Subtitusi Persamaan (22) ke Persamaan (23), maka diperoleh

atau ekuivelaen dengan

$$
z_{0}=\frac{a\left(\frac{\bar{a} z_{0}+\bar{b}}{\bar{c} z_{0}+\bar{d}}\right)+b}{c\left(\frac{\bar{a} z_{0}+\bar{b}}{\bar{c} z_{0}+\bar{d}}\right)+d}
$$

$$
(\bar{a} c+\bar{c} d) z_{0}^{2}+\left(|d|^{2}-|a|^{2}+\bar{b} c-b \bar{c}\right) z_{0}-(a \bar{b}+b \bar{d})=0 .
$$

Perhatikan bahwa 


$$
\begin{aligned}
D & =\left(\left(|d|^{2}+\overline{b c}\right)-\left(|a|^{2}+b \bar{c}\right)\right)^{2}+4(\bar{a} c+\bar{c} d)(a \bar{b}+b \bar{d}) \\
& =\left[\left(|d|^{2}+\overline{b c}\right)+\left(|a|^{2}+b \bar{c}\right)\right]^{2}-4\left(|d|^{2}+\overline{b c}\right)\left(|a|^{2}+b \bar{c}\right)+4(\bar{a} c+\bar{c} d)(a \bar{b}+b \bar{d}) \\
& =\left[\left(|d|^{2}+\overline{b c}\right)+\left(|a|^{2}+b \bar{c}\right)\right]^{2}-4(a d-b c) \overline{(a d-b c)} \\
& =\left[|d|^{2}+|a|^{2}+\overline{b c}+b \bar{c}\right]^{2}-4 .
\end{aligned}
$$

Karena $\bar{a} c+\bar{c} d \neq 0$ dan $D=\left(|a|^{2}+|d|^{2}+b \bar{c}+\bar{b} c\right)^{2}-4 \neq 0$, maka persamaan kuadrat (24) memiliki solusi yaitu

$$
z_{0}^{*}=\frac{\left(|a|^{2}-|d|^{2}+b \bar{c}-\bar{b} c\right)+\sqrt{D}}{2(\bar{a} c+\bar{c} d)} .
$$

Akibatnya, transformasi bilinear konjugat $\bar{T}(z)$ memiliki dua titik tetap yang berhingga.

Akibat 10 [13]. Diberikan transformasi bilinear konjugat $\bar{T}(z)$. Jika $c \neq 0, \bar{a}+d \neq 0$ dan $D=\left(|a|^{2}+|d|^{2}+b \bar{c}+\overline{b c}\right)^{2}-4=0$, maka $\bar{T}(z)$ mempunyai satu titik tetap yang berhingga.

Bukti. Misalkan $z_{0}$ adalah titik tetap dari $\bar{T}(z)$. Karena $\bar{a} c+\bar{c} d \neq 0$ dan $D=\left(|a|^{2}+|d|^{2}+b \bar{c}+\bar{b} c\right)^{2}-4=0$ , maka Persamaan (25) menjadi

$$
z_{0}=\frac{\left(|a|^{2}-|d|^{2}+b \bar{c}-\bar{b} c\right)}{2(\bar{a} c+\bar{c} d)} .
$$

Jadi $\bar{T}(z)$ mempunyai satu titik tetap yang berhingga.

Contoh 1. Transformasi bilinear konjugat

$$
\bar{T}_{1}(z)=\frac{3 i \bar{z}+2 i}{4 i \bar{z}+3}
$$

memiliki dua titik tetap. Hal ini dapat dilihat dari nilai $\bar{a} c+\bar{c} d=12-12 i \neq 0$ dan $D=\left(|a|^{2}+|d|^{2}+b \bar{c}+\bar{b} c\right)^{2}-4=1152 \neq 0$. Titik tetap dari transformasi $\bar{T}_{1}(z)$ adalah $z_{0}=\frac{(1+i) \sqrt{8}}{2}$ dan $z_{1}=-\frac{(1+i) \sqrt{8}}{2}$.

Transformasi bilinear konjugat

$$
\bar{T}_{2}(z)=\frac{-4 i \bar{z}-3}{3 \bar{z}-2 i}
$$

memiliki satu titik tetap. Hal ini dikarenakan nilai dari dari $\bar{a} c+\bar{c} d=6 i \neq 0$ dan $D=\left(|a|^{2}+|d|^{2}+b \bar{c}+\bar{b} c\right)^{2}-4=0$. Titik tetap dari transformasi $\bar{T}_{1}(z)$ adalah $z_{0}=-i$.

Teorema 11 [13]. Diberikan transformasi bilinear konjugat $\bar{T}(z)$. Jika $c=0, \bar{a}+d \neq 0$ dan $|d|^{2}-|a|^{2}+\bar{b} c-b \bar{c} \neq 0$, maka $\bar{T}(z)$ mempunyai satu titik tetap yang berhingga dan satu titik tetap tak berhingga.

Bukti. Diketahui $c=0$, maka $a d=1$ dan $|d|^{2}-|a|^{2} \neq 0$. Akibatnya, $|a| \neq 0$ atau $|a| \neq 1$ serta $|d| \neq 0$ atau $|d| \neq 1$. Diperoleh

$$
\bar{T}(z)=\frac{a \bar{z}+b}{d}=a^{2} \bar{z}+a b .
$$


Diperoleh $\bar{T}(\infty)=\infty$. Jadi $\infty \in \mathbf{C}^{*}$. Selanjutnya, misalkan $z_{0} \in \mathbf{C}$ adalah titik tetap $\bar{T}(z)$, maka

$$
\overline{z_{0}}=\overline{a^{2}} z_{0}+\overline{a b}
$$

Dengan mensubtitusi (29) ke (28) diperoleh

$$
z_{0}=a^{2} \overline{a^{2}} z_{0}+a|a|^{2} \bar{b}+a b .
$$

Jadi titik tetap transformasi bilinear konjugat $\bar{T}(z)$ adalah

$$
z_{0}=\frac{a|a|^{2} \bar{b}+a b}{1-|a|^{4}} \text {. }
$$

\section{KESIMPULAN}

Titik tetap transformasi bilinear ditentukan dari nilai koefisien-koefisiennya. Transformasi bilinear dapat memiliki dua titik tetap berhingga, satu titik tetap berhingga dan satu titik tetap tak berhingga atau hanya memiliki satu titik tetap tak berhingga. Titik tetap invers transformasi bilinear sama dengan titik tetap transformasi bilinear. Sementara transformasi bilinear konjugat dapat memiliki satu titik tetap berhingga atau dua titik tetap berhingga.

\section{DAFTAR PUSTAKA}

[1] S. Lin and M. Chen, "Applications of Mobius transform in image processing and cryptography," in 2010 2nd International Conference on Signal Processing Systems, Jul. 2010, vol. 2, pp. V2-257-V2-259, doi: 10.1109/ICSPS.2010.5555500.

[2] P. Niamsup, "A Note on the Characteristics of the Mobius Transformations," J. Math. Anal. Appl., vol. 248, pp. 203-215, 2000, doi: 10.1109/JRPROC.1943.234348.

[3] L. Jing, "A New Characteristic of Möbius Transformations by Use of Polygons Having Type A," J. Math. Anal. Appl., vol. 324, no. 1, pp. 281-284, 2006, doi: 10.1016/j.jmaa.2005.12.015.

[4] D. S. Mackey, N. Mackey, C. Mehl, and V. Mehrmann, "Möbius transformations of matrix polynomials," Linear Algebra Appl., vol. 470, pp. 120-184, 2015, doi: 10.1016/j.laa.2014.05.013.

[5] O. Demirel, "A characterization of Möbius transformations by use of hyperbolic triangles," J. Math. Anal. Appl., vol. 398, no. 2, pp. 457-461, 2013, doi: 10.1016/j.jmaa.2012.05.044.

[6] P. Kaur, "The Fixed Points of Mobius Transformations," Int. J. Electron. Eng., vol. 9, no. 1, pp. 38-42.

[7] N. Yilmaz Özgür, "On the n-Transitivity of The Group of Möbius Transformations on C $\infty$," Chaos, Solitons and Fractals, vol. 40, no. 1, pp. 106-110, 2009, doi: 10.1016/j.chaos.2007.07.024.

[8] Y. Shihai and A. Fang, "A new characteristic of Möbius Transformations in Hyperbolic Geometry," J. Math. Anal. Appl., vol. 319, no. 2, pp. 660-664, 2006, doi: 10.1016/j.jmaa.2005.05.082.

[9] H. Huang, "Discrete Subgroups of Möbius Transformations," J. Math. Anal. Appl., vol. 397, no. 1, pp. 233-241, 2013, doi: $10.1016 /$ j.jmaa.2012.07.029.

[10] H. Haruki and T. M. Rassias, "A New Invariant Characteristic Property of Möbius Transformations from the Standpoint of Conformal Mapping," J. Math. Anal. Appl., vol. 181, no. 2, pp. 320-327, 1994, doi: 10.1006/jmaa.1994.1024.

[11] A. Barrlund, H. Wallin, and J. Karlsson, "Iteration of Möbius Transformations and Attractors on the Real Line," Comput. Math. with Appl., vol. 33, no. 1-2, pp. 1-12, 1997, doi: 10.1016/s0898-1221(96)00215-5.

[12] D. G. Zill and P. D. Shanahan, A First Course in Complex Analysis with Applications. Boston: Jones and Bartlett Publishers, 2003.

[13] M. O. Gonzalez, "Classical complex analysis.” Marcel Dekker Inc., New York, 1992.

[14] H. K. Pathak, Complex Analysis and Applications. Raipur: Springer, 2018.

[15] J. W. Brown and R. V. Churcill, Complex Variables and Applications, 9th ed. New York: Mc Graw Hill, 2015. 
